\title{
Analytical Model of an Induction Motor Taking into Account the Punching Process Influence on the Material Properties' Change of Lamination
}

\author{
Maria Dems *(D), Zbigniew Gmyrek (D) and Krzysztof Komeza (D) \\ Institute of Mechatronics and Information Systems, Lodz University of Technology, 90924 Lodz, Poland; \\ zbigniew.gmyrek@p.lodz.pl (Z.G.); krzysztof.komeza@p.lodz.pl (K.K.) \\ * Correspondence: maria.dems@p.lodz.pl; Tel.: +48-42-631-25-81
}

Citation: Dems, M.; Gmyrek, Z.; Komeza, K. Analytical Model of an Induction Motor Taking into Account the Punching Process Influence on the Material Properties' Change of Lamination. Energies 2021, 14, 2459. https://doi.org/10.3390/en14092459

Academic Editor:

Sheldon Williamson

Received: 23 March 2021

Accepted: 23 April 2021

Published: 26 April 2021

Publisher's Note: MDPI stays neutral with regard to jurisdictional claims in published maps and institutional affiliations.

Copyright: (C) 2021 by the authors. Licensee MDPI, Basel, Switzerland. This article is an open access article distributed under the terms and conditions of the Creative Commons Attribution (CC BY) license (https:// creativecommons.org/licenses/by/ $4.0 /)$.

\begin{abstract}
The technologies of cutting the cores of electric machines change the magnetic properties and the loss of the electrical sheets used, affecting the machine's parameters, mainly power losses and efficiency. This is particularly important in the case of induction motors, which are a significant consumer of electricity. Therefore, the problem of increasing their efficiency is important from the point of view of environmental impact. The article presents a method of approximating a material's magnetic properties based on the results of measurements carried out with specimens of various widths. The presented method allows for an approximate representation of the changes in the structure of the material caused by the cutting technology. It is used in the analytical method for calculating motor parameters, and gives results that are in good agreement with the measurement. This method can determine the operating parameters of electrical machines of various sizes and rated powers.
\end{abstract}

Keywords: analytical methods; magnetic materials; induction motors; induction motor efficiency

\section{Introduction}

The production of electric motor cores made of ferromagnetic laminations requires, among others, the implementation of cutting process. Punching is the cheapest and fastest solution used in electric motor mass production. Unfortunately, its implementation leads to material property deterioration of the ferromagnetic material (magnetizability, specific iron loss) [1-3]. This effect is especially visible in cores having relatively small size elements (with a width of a few $\mathrm{mm}$ ). Ignoring the deterioration of the core properties in such a case leads to significant differences between measured and calculated operating parameters like motor efficiency. The problem concerning determination of the material properties in the damaged zone, has been known for years. Research works related to currently used non-invasive measurement techniques [4-6], enabling estimation of the zone's width and material properties close to the cut edge, can be indicated here. Apart from measurement techniques, there are also calculation methods based on analytical or FEM modeling, e.g., [7-19]. In the literature, we can find two approaches enabling estimation of the damaged zone width and determination its material properties: the first one is based on the calculation of the zone size (adopted as homogeneously damaged) and its equivalent material properties, and the second one, allowing for the determination of local material properties related to the so-called induction profiles in this zone. The determination of the zone size (assumed to be made of a homogeneous material) and its material properties, is possible in an analytical way, for example, by applying the algorithm previously proposed and described in the literature [7,20], by one of the authors of this paper. In the proceeding algorithm, we used the results of measurements carried out for several widths of the tested material strip-such testing was carried out in the single strip tester system. From the point of view of the currently conducted research, the use of this 
algorithm is appropriate and sufficient. The result of the work was determination of the zone width of the damaged material and its properties.

The paper uses the proposed approach to calculating an induction motor's operating parameters, especially losses and efficiency. For this purpose, an analytical model based on the machine equivalent circuit was used. In this model, the magnetization and loss characteristics determined by measurement for a ring specimen with a width of $10 \mathrm{~mm}$ were used to calculate the magnetizing current and the motor core's basic losses. Measurements were carried out for a wide frequency range (from $10 \mathrm{~Hz}$ to $14,400 \mathrm{~Hz}$ ) and the maximum possible flux density for this frequency. Basic losses in stator teeth were calculated as the sum of losses in four layers at the teeth' height for the actual value of induction occurring in each layer.

To map the impact of insulation damage at the edges of the stator and rotor teeth caused by the core punching technology, additional magnetization and loss characteristics were introduced in the calculation model, converted from the measured characteristics to the actual dimensions of the stator and rotor teeth and the motor yoke, using the proprietary calculation algorithm, described later in the article. It should be emphasized, that this part of the work clearly indicates the need to take into account material characteristics determined for a specific width of the motor core fragment.

Additional losses in the motor core were calculated according to the method presented in [21], using the material properties measured for a $10 \mathrm{~mm}$ wide specimen. It should be added that the applied analytical circuit model also takes into account non-linear phenomena occurring in the motor, such as saturation of the magnetic circuit and current displacement in the rotor cage bars. The results of calculating the motor's losses and efficiency obtained using material characteristics for a specimen with a constant width and those with different widths, were compared with the measurement results. They clearly indicate the need to take into account the size (the width) of the motor element, in the process of determining the operating parameters of motors having relatively small geometric sizes.

\section{Analytical Method for Determining the Size of Uniform Damaged Zone}

Analytical determination of model parameters is commonly used in engineering practice. It allows for quick and sufficiently accurate execution of calculations. The applied algorithm for determining the size and material properties of the zone damaged by punching is based on the assumption that a zone has a uniform, equivalent propertiesFigure 1. This means that for macroscopic calculations (just like in analytical models), the simulation and measurement results (e.g., material specific loss, magnetizability) are consistent. However, the actual local values may be different than those resulting from the model. As mentioned, the model used was developed several years ago so that this paper will present its main assumptions, and the reader can find detailed information in [7].

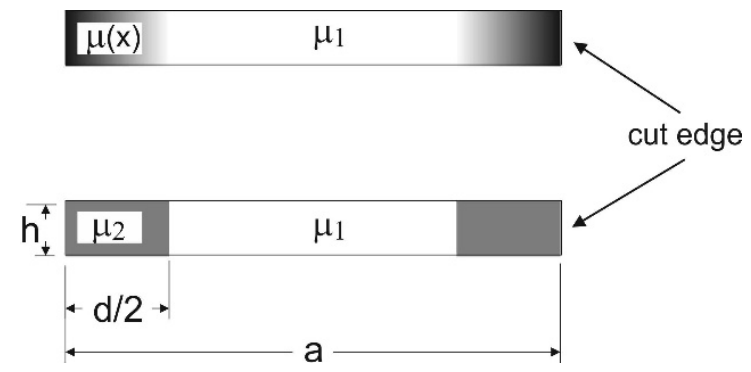

Figure 1. Comparison of a material model with properties dependent on the distance from the cut edge (upper) and a model with equivalent, homogeneous material properties (lower).

The adopted material model, containing areas with uniform, equivalent magnetic permeability, is equivalent to the material model in which the magnetic permeability is a function of the distance from the cut edge. For partially damaged material, an equation 
representing the whole magnetic flux passing through a strip cross-section can be written as follows:

$$
\Phi=h d \mu_{2} H_{D}+h(a-d) \mu_{1} H_{D}=h d H_{D} \int_{0}^{d / 2} \mu(x) d x+h(a-d) \mu_{1} H_{D}
$$

where $\Phi$ is the whole magnetic flux penetrating strip cross-section of partially damaged strip, $h$ is the strip height, $d / 2$ is the damaged zone width, $a$ is the investigated strip width, $\mu(x), \mu_{1}$ and $\mu_{2}$ are the magnetic permeabilities (depending on $H_{D}$ ) of non-uniform, undamaged and damaged material respectively, $H_{D}$ is the magnetic field strength on the strip surface, in case of partially damaged material.

For a strip with non-degraded material, leading the same magnetic flux $\Phi$ as in Equation (1), a similar equation can be written:

$$
\Phi=h a \mu_{3} H_{N D}
$$

where $\Phi$ is the whole magnetic flux penetrating strip cross-section of undamaged material, $\mu_{3}$ is the magnetic permeabilities of non-degraded material (depending on $\left.H_{N D}\right), H_{N D}$ is the magnetic field strength on the strip surface, in case of undamaged material.

It is worth remembering that, to achieve the same maximum value of the total flux in the strip cross-section, a different value of the magnetic field strength is necessary in a material with damaged zones compared to a material that does not have such zones. It follows that the values of $\mu_{1}$ and $\mu_{3}$ are different. The Equations (1) and (2) adopt a uniform distribution of the induction amplitude, in damaged and undamaged areas. Such an assumption results in the implementation of measurements, necessary to determine the size and equivalent material properties of the damaged zone, with relatively low frequency (the authors executed measurements at $50 \mathrm{~Hz}$ ).

Similarly, using the Poynting theory, it is possible to write the following equation for specific iron loss in case of partly damaged material [19] —additional explanations can be found in Appendix A:

$$
p=c h d \sqrt{\mu_{2}} H_{D}^{2}+c(a-d) h \sqrt{\mu_{1}} H_{D}^{2}
$$

where $c$ is the material constant.

For a strip with non-degraded material, the following equation can be written as:

$$
p=c a h \sqrt{\mu_{3}} H_{N D}^{2}
$$

After performing the necessary transformations, we obtain the relationship between the damaged material zone's width, the thickness of the strip, and the measured data determined in a specific way [7]:

$$
\frac{d}{a}=\frac{C C^{2}}{2 \sqrt{N} C C-A A}
$$

where $C C, N, A A$ are parameters determined on the base of executed measurements.

The above-mentioned coefficients, described in more detail in [20], were determined based on the following dependencies, containing the measurement data determined as shown in Figure 2:

$$
\begin{gathered}
N=\frac{B^{* *} H_{N D}}{H_{D} B^{*}} \\
C C=\sqrt{N}-\frac{p_{D}}{p_{N D}} \frac{H_{N D}^{2}}{H_{D}^{2}} \\
A A=N-\frac{H_{N D}}{H_{D}}
\end{gathered}
$$


where $B^{*}$ is the flux density (read from the $B-H$ curve of the partially damaged material) at $H_{D}$ magnetic field strength, that can be selected anywhere in the measured range, $B^{* *}$ is the flux density (read from the $B-H$ curve of the undamaged material) at the same $H_{D}$ magnetic field strength, $p_{N D}$ and $p_{D}$ are measured specific loss, for $H_{N D}$ and $H_{D}$, respectively.

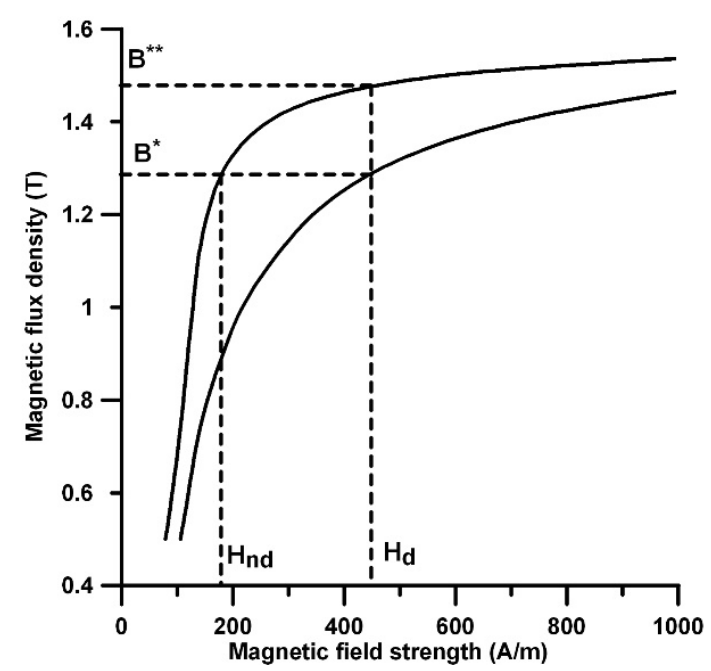

Figure 2. The idea of determining physical quantities $B^{*}$ and $B^{* *}$ flux densities, and $H_{N D}$ and $H_{D}$ magnetic field strengths. The lower $B-H$ curve - for the partially damaged material, the upper $B-H$ curve-for the material without the damaged zone [20].

\section{Determination of Material Properties of the Damaged Zone at $50 \mathrm{~Hz}$}

The width of uniformly damaged zone, determined according to the formulas described in the previous section, should be linked to the measurement results. The authors' team performed measurements of the $B-H$ magnetization curve and the specific iron loss curve of a punched toroidal specimen (at $50 \mathrm{~Hz}$ ) made of the M470-50A material (strip thickness is $0.5 \mathrm{~mm}$ ) - see Figure 3. From the research goal point of view, which is determination of the equivalent width of the damaged material zone, the measurement frequency is not chosen a priori and may be different than $50 \mathrm{~Hz}$. However, it should ensure a uniform magnetic flux distribution inside the specimen (to avoid ambiguity of obtained result) and relatively large recorded measuring signals (e.g., induced voltage and magnetizing current). The toroidal specimen, assembled with 20 laminations, had the following dimensions: outer diameter $420 \mathrm{~mm}$, inner diameter $400 \mathrm{~mm}$. For comparison, these characteristics were also measured for the core cut with the EDM method, thus obtaining a reference base. The EDM method is one of the lamination cutting methods available in industry, and consists in removing the material through a series of rapid repeating current discharges between two electrodes. For five points located near the $B-H$ curve's knee, the values necessary to determine the width of the uniformly degraded material were read, and then the obtained result was averaged. For further calculations, using the authors' method described in Section 2 and the results of measurements executed with the toroidal specimen described above, the width of the damaged material zone in the test material was calculated as $1.69 \mathrm{~mm}$ for each cut edge.

The next step in preparing the data necessary for use in an induction motor's analytical model was the determination of the magnetization curves and specific iron loss curves (for $50 \mathrm{~Hz}$ ) for various specimen widths. Knowing the estimated damaged material zone width, the following algorithm was implemented:

- $\quad$ for the given $H$ magnetic field strength, knowing the magnetization curves for the undamaged material and the $10 \mathrm{~mm}$ wide specimen, the $B-H$ curves of a uniformly 
damaged material with a width of $3.38 \mathrm{~mm}$ (twice the width of the damaged zone) were determined, according to the following formula:

$$
B_{D}=\frac{10 \cdot B_{10}-6.62 \cdot B_{N D}}{3.38}
$$

where $B_{D}, B_{10}, B_{N D}$ are the magnetic flux density in uniformly damaged material, in $10 \mathrm{~mm}$ width specimen and non-degraded material respectively, 10, 6.62 and 3.38 are width in $\mathrm{mm}$, of the specimen, non-degraded part of specimen and uniformly degraded part of specimen respectively.

- the identical procedure for the specific iron loss of damaged material zone was carried out using the following relationship (for specified $H$ magnetic field strength)

$$
p_{D}=\frac{10 \cdot p_{10}-6.62 \cdot p_{N D}}{3.38}
$$

where $p_{D}, p_{10}, p_{N D}$ are the specific iron loss in uniformly damaged material, in $10 \mathrm{~mm}$ width specimen and non-degraded material respectively, 10, 6.62 and 3.38 are width in $\mathrm{mm}$, of the specimen, non-degraded part of specimen and uniformly degraded part of the specimen, respectively.

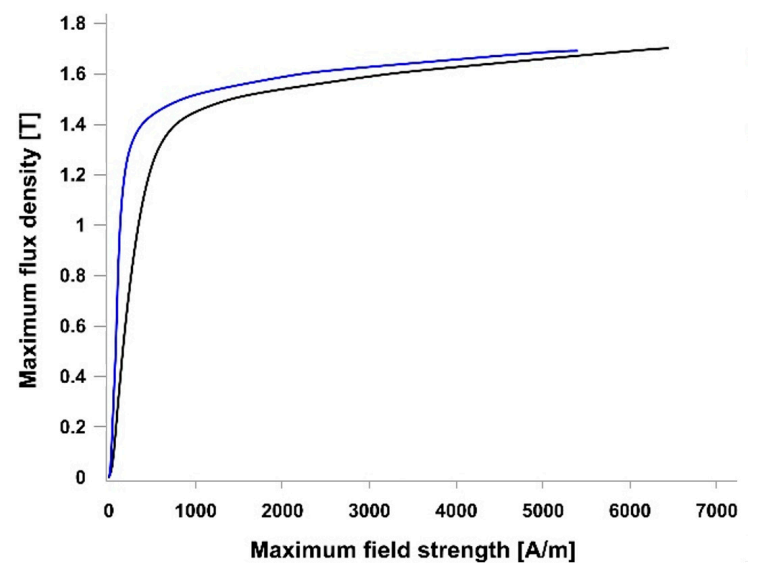

(a)

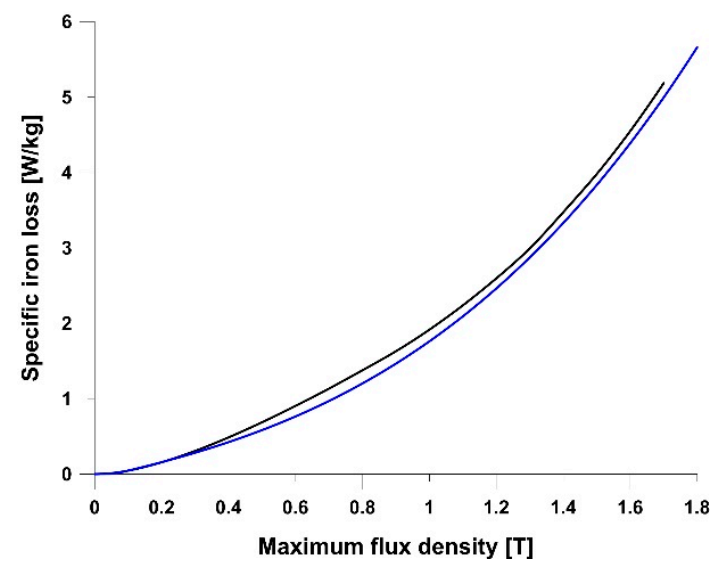

(b)

Figure 3. The measured at $50 \mathrm{~Hz}, \mathrm{~B}-\mathrm{H}$ curves (a) and specific iron loss (b) for M470-50A material. Black curve-for partially damaged material, blue one-for undamaged material.

Thus, it was easy to determine the resultant $B-H$ curves and specific iron loss curves for any strip width (greater than $3.38 \mathrm{~mm}$ )—Equation (11). The specific iron loss curves should now be presented as a magnetic flux density function, which was performed using previously determined $B-H$ curves for the degraded zone's material—see Figure 4:

$$
B_{x x}=\frac{3.38 \cdot B_{D}+(x x-3.38) \cdot B_{N D}}{x x}
$$

where $B_{\mathrm{xx}}, B_{D}$ and $B_{N D}$ are the magnetic flux density in partly damaged material (having $X X \mathrm{~mm}$ width), in uniform damaged part of specimen and non-degraded material part, respectively. 


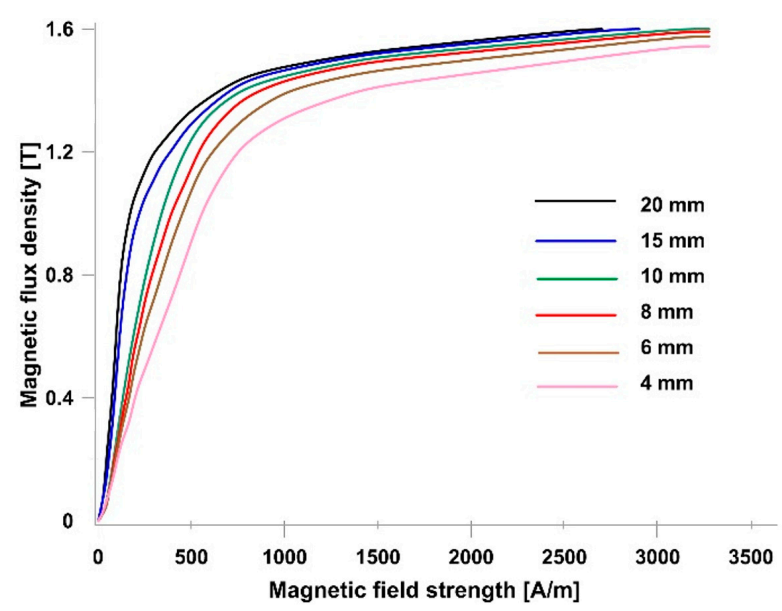

(a)

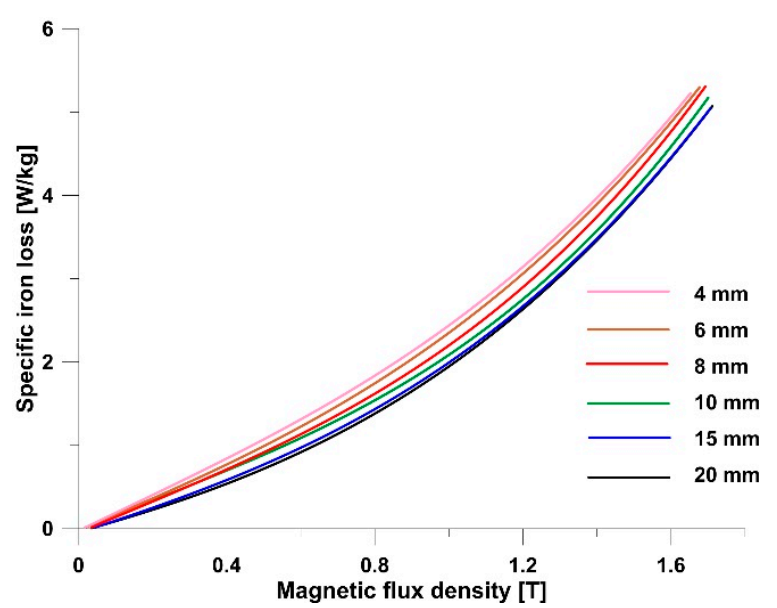

(b)

Figure 4. The measured (green) and calculated $B-H$ curves (a) and specific iron loss curves (b), for $50 \mathrm{~Hz}$, and varying strip width.

\section{Determination of Material Properties of the Damaged Zone, Based on Measurements Executed at Frequencies Greater Than $50 \mathrm{~Hz}$}

The efficiency determination of a modeled induction motor requires the knowledge of the material properties not only for the supply frequency $(50 \mathrm{~Hz})$ but also for higher frequencies, allowing to estimate additional iron losses occurring in the stator core and on the rotor core surface. The main problem that arises here concerns the increased degree in hysteresis loss component (possibly excess component) resulting from the grain structure destruction, which results from the punching process. For eddy-current loss, the matter is simpler because the effect of grain structure destruction on electrical conductivity change can be ignored. The increase in these losses can be estimated only based on the knowledge of the magnetic field strength increase and magnetic permeability. Moreover, for relatively high frequencies (for the tested material, it is more than $1 \mathrm{kHz}$ ), we can no longer talk about a uniform distribution of the flux density amplitude inside the strip cross-section section - in the induction range we are interested in, at example frequencies $200 \mathrm{~Hz}$ and $2000 \mathrm{~Hz}$, the skin-layer thickness is $0.3-1.3 \mathrm{~mm}$ and $0.12 \mathrm{~mm}$, respectively. Thus, from this paper's point of view, estimating the increase in hysteresis loss for even distribution of flux density inside the sheet was adopted (taking into account their decreasing share in total iron losses with increasing frequency). Based on the results of measurements carried out on a specimen cut with the EDM method, classic loss components were found. Then, for $50 \mathrm{~Hz}$, the eddy current loss determined from the EDM cut specimen was subtracted from the total iron loss measured in punched toroidal specimen (10 $\mathrm{mm}$ wide). In this way, the total hysteresis loss (for a $10 \mathrm{~mm}$ punched toroidal specimen) was determined. Hysteresis losses in the damaged part of the material were determined based on the following relationship:

$$
P_{H d}\left(B_{D}\right)=P_{H t}\left(B_{A V}\right)-P_{H u}\left(B_{u}\right)
$$

where $P_{H d}, P_{H t}$, and $P_{H u}$ are the hysteresis losses for the damaged part of the material, the total hysteresis loss measured for the $10-\mathrm{mm}$ wide punched toroidal specimen, and the hysteresis loss for the undamaged part of the material, respectively. $B_{D}, B_{A V}$ and $B_{u}$ are the flux density for the damaged part of the material, average flux density for the $10-\mathrm{mm}$ toroidal core, and the flux density for the undamaged part of the 10-mm toroidal specimen respectively.

Therefore for the purposes of calculations performed for frequencies greater than $50 \mathrm{~Hz}$, the starting point for determining the total iron loss in the strip with a given width and pointed frequency, were the measurements executed for toroidal specimen with a width of $10 \mathrm{~mm}$, cut by EDM technology and punched. Using known, the previously 
calculated width of the damaged material zone, the total iron loss (containing hysteresis and eddy current losses) was determined for the material of the damaged zone-Equation (13):

$$
P_{D}\left(B_{D}\right)=P_{p}\left(B_{A V}\right)-\frac{10-2 \cdot 1.69}{10} P_{10 E D M}\left(B_{u}\right)
$$

where $P_{D}\left(B_{\mathrm{D}}\right)$ is the total iron loss at the damaged material zone, at $B_{D}$ flux density, $P_{10 E D M}\left(B_{u}\right)$ is the total iron loss of the $10 \mathrm{~mm}$ strip cut with the EDM technology, at $B_{u}$ flux density, $P_{p}\left(B_{A V}\right)$ is the total iron loss of punched $10 \mathrm{~mm}$ strip, at $B_{A V}$ flux density, the $B_{D}$ flux density is linked with damaged material, the $B_{A V}$ is the average flux density linked with punched strip, whereas the $B_{u}$ flux density is linked with undamaged part of the material. For a punched strip with a given width, knowing the magnetization curves of the "green" material and the material of the damaged zone, is possible unique definition of the dependencies between the $B_{A V}$ measured average induction (over a strip cross-section) determined for a punched strip, and $B_{u}$ and $B_{D}$ inductions.

By changing the participation of "green" material, for a given $B_{A V}$ induction, the specific iron losses at pointed frequency, for the strip with particular width were calculated. Next, these specific losses were compared with those measured for a 10-mm toroidal core and with those measured for the specimen cut by the EDM method-see Figure 5.

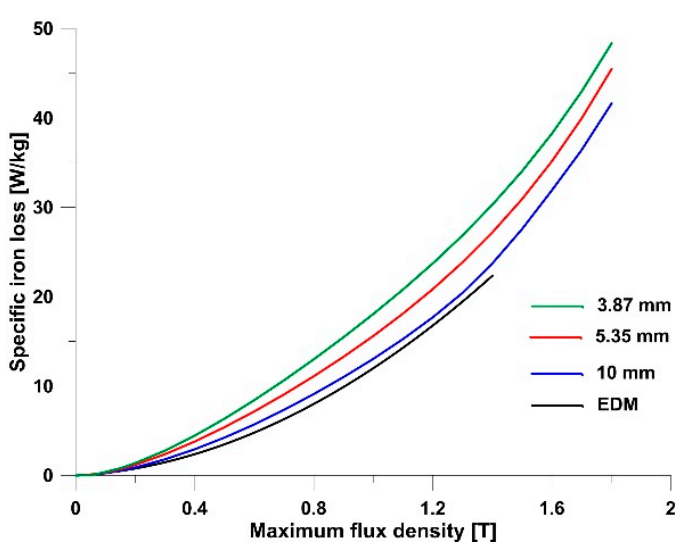

(a)

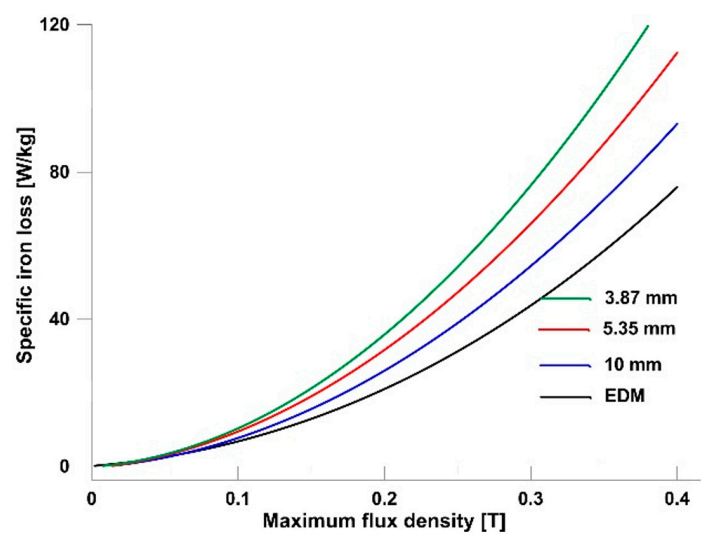

(b)

Figure 5. The comparison of specific iron loss, for various strip widths, for $200 \mathrm{~Hz}$ (a), and for $2000 \mathrm{~Hz}$ (b).

5. Calculations of Losses and Efficiency of Selected Induction Motors Taking into Account the Influence of Various Specimen Widths on $B-H$ Curves and Specific Iron Loss Curves

To initially assess the impact of the core punching technology on the induction motor's losses and efficiency, calculations of the electromagnetic parameters of two low-power three-phase induction motors were performed. Motor 1 is dedicated to driving a centrifuge for blood plasma, with a shaft axis height $\mathrm{h}=56 \mathrm{~mm}$ and rated power $\mathrm{P}_{\mathrm{r}}=200 \mathrm{~W}$. The motor is designed to work at a voltage of $230 \mathrm{~V}$ and a frequency of $300 \mathrm{~Hz}$. Motor 2 is dedicated to driving an industrial washing machine with a shaft axis height $\mathrm{h}=71 \mathrm{~mm}$, works over a wide frequency range, that is, $10 \mathrm{~Hz}, 20 \mathrm{~Hz}$, and $350 \mathrm{~Hz}$, at a voltage of $230 \mathrm{~V}$ at a frequency of $350 \mathrm{~Hz}$, and a proportionally reduced voltage for lower frequencies. The stator and rotor cores of both motors were made of M470-50A electrical sheet, $0.5 \mathrm{~mm}$ thick. The basic design parameters of both machines are presented in Table 1.

The analytical model, based on the induction motor's equivalent circuit, was used for the calculations. This model considers the influence of the phenomenon of current displacement on the rotor parameters by the elementary conductor method and the influence of the saturation phenomenon by introducing the saturation factor depending on the resultant flow in the stator and rotor windings. The basic losses in the stator teeth were calculated for the fundamental harmonic of the field, when the tooth was divided along 
the height into four layers, as the sum of the losses in each layer for the actual value of the induction occurring in this layer, while the basic losses in the stator yoke were calculated for the mean value of the induction in the yoke. These losses were calculated both for the magnetization and specific losses characteristics determined by measurement in a wide frequency range with a constant width of the ring sample equal to $10 \mathrm{~mm}$, and for the calculated characteristics for the actual widths of the teeth and the stator yoke. When calculating additional surface and pulsation losses in the stator core and surface losses in the rotor core, the loss characteristics determined experimentally for a sample with a constant width were used. The surface losses were calculated as the sum of the losses from individual induction harmonics, and for each harmonic were determined as the product of the approximated loss for the actual induction value and the frequency of this harmonic, and the surface mass of the tooth layer. The teeth's volume was calculated as the tooth surface product and the penetration depth of the field of each harmonic into the tooth [21], which was corrected based on field calculations. The total core losses were calculated as the sum of the basic losses plus additional losses in the stator core and additional surface losses in the rotor core.

Table 1. Electromagnetic parameters of the investigated induction motors.

\begin{tabular}{ccc}
\hline Parameter & Motor 1 & Motor 2 \\
\hline Number of pole pairs & 2 & 4 \\
Stator core outer diameter (mm) & 87.4 & 120.0 \\
Stator core inner diameter (mm) & 44.0 & 78.0 \\
Core length (mm) & 32.0 & 120.0 \\
Number of stator slots & 18 & 36 \\
Number of rotor slots & 11 & 32 \\
Stator tooth mean width (mm) & 3.87 & 3.25 \\
Rotor tooth mean width (mm) & 5.35 & 3.06 \\
Stator yoke height $(\mathrm{mm})$ & 12.52 & 7.52 \\
Rotor yoke height $(\mathrm{mm})$ & 4.50 & 12.62 \\
\hline
\end{tabular}

For both motors, the calculations were made in two versions: using the magnetization and loss characteristics of the mentioned lamination measured for a ring core with a width of $10 \mathrm{~mm}$, and determining both the magnetic voltage and losses in individual core elements based on different magnetization and loss characteristics converted to the actual width of the teeth and yoke in motor cores. The calculation results were compared with the measurement results for the tested machines. It should be noted that the loss characteristics taking into account the specimen width, were used only in determining the basic losses in the core. Separate research is required to consider the influence of technology on additional losses in the core caused by higher harmonics of the magnetic induction. Figure 6 shows the current waveforms in the stator winding, total losses, core losses, and efficiency of motor one as a function of the torque on the shaft, with the motor being supplied with the rated voltage at $300 \mathrm{~Hz}$.

Figure 7 shows analogous characteristics for the motor 2 when the motor is powered with the rated voltage at $350 \mathrm{~Hz}$.

Table 2 summarizes the basic electromagnetic parameters of both motors loaded with the rated torque on the shaft, calculated using the magnetization and loss characteristics measured for a $10 \mathrm{~mm}$ wide ring specimen and for the characteristics converted to the actual width of the teeth and yoke of the motor core.

Based on Figures 6 and 7 and Table 2, it can be concluded that the application of the magnetization characteristics and losses depending on the width of the teeth and the stator yoke to the calculations of the basic losses in the core caused the basic losses in the core for the first motor to increase by $8.2 \%$, and consequently to decrease efficiency by $0.33 \%$, while for the slightly larger second motor, the basic losses in the core increased by $12.5 \%$, while the decrease in efficiency amounted to $0.59 \%$. It should be expected that taking into account the influence of the core punching technology on additional losses in the core will 
result in a further increase in core losses and a greater decrease in the efficiency of motors, and this phenomenon will occur the more strongly, the higher the frequency of the voltage supplying the motor.

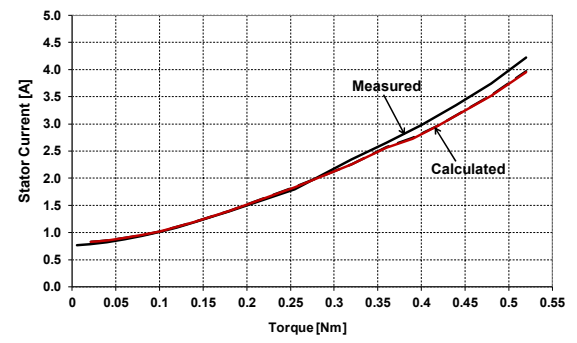

(a)

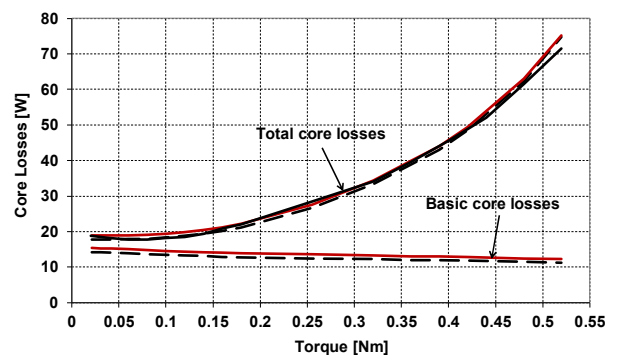

(c)

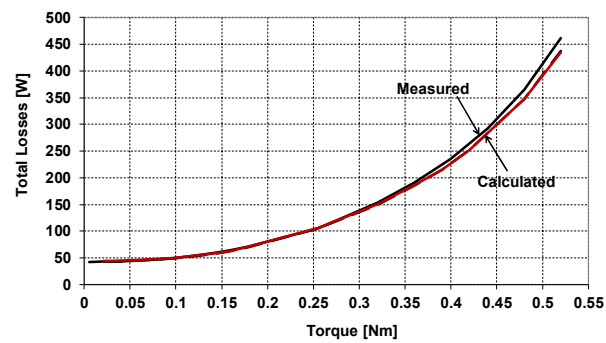

(b)

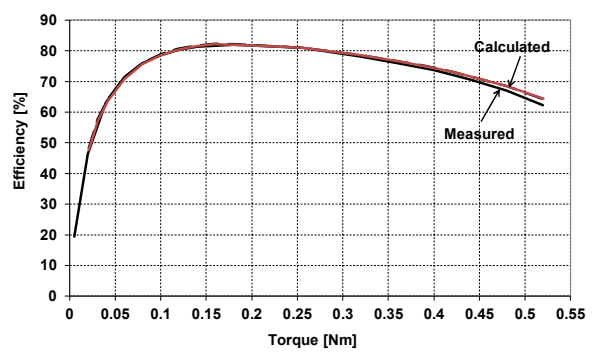

(d)

Figure 6. The measured at $300 \mathrm{~Hz}$ and calculated, stator current (a), total losses (b), core losses (c) and efficiency (d) for motor 1. Solid black curve-measured, dashed black curve - calculated for the characteristics measured for the specimen ring with a width of $10 \mathrm{~mm}$, red one-calculated for the characteristics converted to the actual width of the teeth and yoke of the motor core.

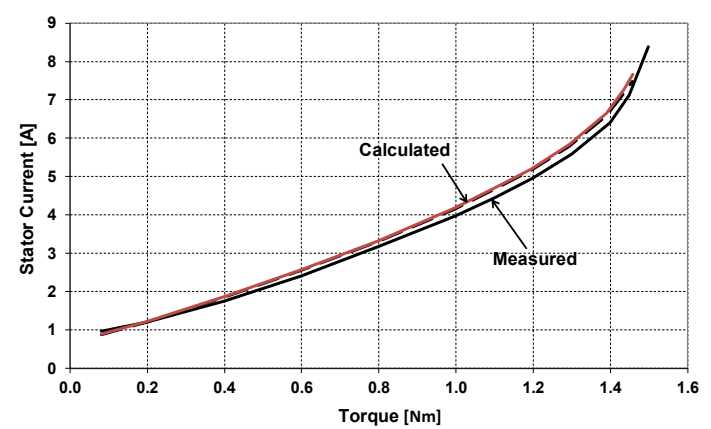

(a)

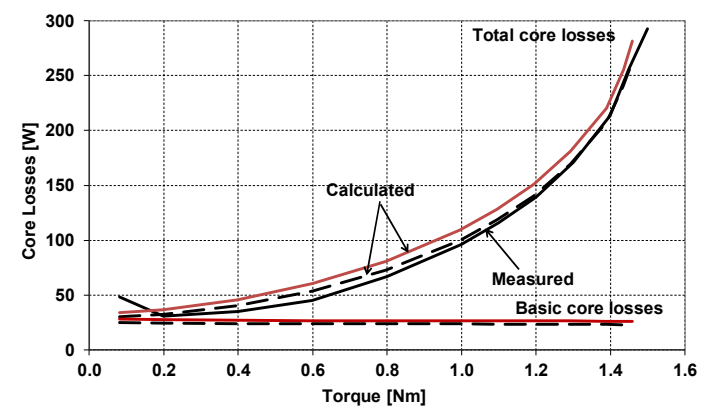

(c)

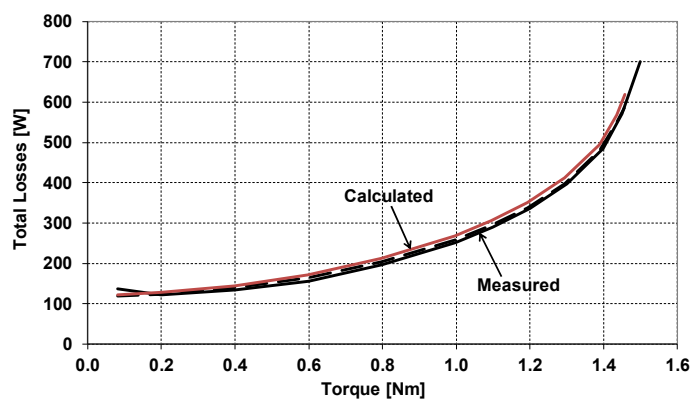

(b)

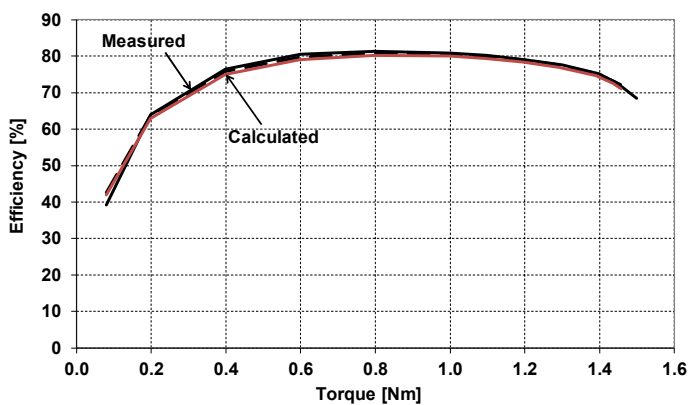

(d)

Figure 7. The measured at $350 \mathrm{~Hz}$ and calculated, stator current (a), total losses (b), core losses (c) and efficiency (d) for motor 1. Solid black curve-measured, dashed black curve - calculated for the characteristics measured for the specimen ring with a width of $10 \mathrm{~mm}$, red one-calculated for the characteristics converted to the actual width of the teeth and yoke of the motor core. 
Table 2. Electromagnetic parameters of motors determined for the characteristics measured for a specimen with a constant width, and specimen with a width corresponding to the cores' actual dimensions.

\begin{tabular}{|c|c|c|c|c|}
\hline \multirow{2}{*}{$\begin{array}{c}\text { Parameter } \\
\text { Specimen Width }\end{array}$} & \multicolumn{2}{|c|}{ Motor 1} & \multicolumn{2}{|c|}{ Motor 2} \\
\hline & $10 \mathrm{~mm}$ & actual & $10 \mathrm{~mm}$ & Actual \\
\hline the frequency of the voltage $(\mathrm{Hz})$ & 300 & 300 & 350 & 350 \\
\hline average value of the supplied voltage $(\mathrm{V})$ & 221.5 & 221.5 & 221.4 & 221.4 \\
\hline electromagnetic torque $(\mathrm{Nm})$ & 0.108 & 0.108 & 1.3 & 1.3 \\
\hline motor shaft power $(\mathrm{W})$ & 200 & 200 & 1375 & 1375 \\
\hline phase current in the stator winding (A) & 1.06 & 1.06 & 5.79 & 5.84 \\
\hline magnetizing current $(\mathrm{A})$ & 0.7605 & 0.7608 & 0.585 & 0.589 \\
\hline $\begin{array}{c}\text { mean value of the induction in stator } \\
\text { teeth }(\mathrm{T})\end{array}$ & 0.850 & 0.850 & 0.328 & 0.328 \\
\hline $\begin{array}{c}\text { mean value of the induction in stator } \\
\text { yoke }(\mathrm{T})\end{array}$ & 0.760 & 0.760 & 0.420 & 0.420 \\
\hline $\begin{array}{c}\text { mean value of the induction in rotor } \\
\text { teeth }(\mathrm{T})\end{array}$ & 0.971 & 0.971 & 0.373 & 0.373 \\
\hline basic core losses $(\mathrm{W})$ & 13.39 & 14.49 & 23.27 & 26.18 \\
\hline total core losses (W) & 18.50 & 19.58 & 169.3 & 181.0 \\
\hline total motor losses $(\mathrm{W})$ & 50.76 & 51.78 & 398.2 & 411.9 \\
\hline motor efficiency $(\%)$ & 79.76 & 79.43 & 77.54 & 76.95 \\
\hline
\end{tabular}

\section{Experimental Setup}

Core loss measurements were executed in the measuring system, containing all necessary components described below. The motor was powered either from the mains or from a PWM inverter (FR-D720S-100SC-EC, (Mitsubishi Electric, Tokyo, Japan) with 1-phase power supply working with $14.5 \mathrm{kHz}$ PWM switching frequency to avoid additional losses, and sine evaluated modulation control, $3.8 \mathrm{kVA}$ rated output capacity, and $10 \mathrm{~A}$ rated current (control methods: V/f control). The HD-715-8NA (Magtrol Inc, Buffalo NY, USA) hysteresis braking system provides precise torque loading independent of shaft speed with the accuracy: $\pm 0.25 \%$ (full scale) was used as the load. They were measured using precise current transducers and a multi-channel analog-to-digital converter of instantaneous currents and voltages (two NI-PCI-6133 measuring cards (National Instruments, Austin, TX, USA), with simultaneous sampling with $0.3 \mathrm{M}$ samplings/s), as well as rotational speed and load torque. The measurement was controlled by a measuring system running under the control of the LabView program. Based on the measured voltage and current values, the shaft's output power, input power, RMS values of phase voltages, and currents were calculated. The winding resistance was measured after the measurement following IEC 60034-2-1 standard (also IEEE 112) and IEC Std 60034-2-3. The meters used satisfied the requirements of the above standards including. Additionally, the temperature of the stator and rotor windings was measured by thermocouples built-in during the model's construction, with the signal from sensors in the rotor being transmitted wirelessly to the external system. An additional element increasing the measurements' accuracy was measuring mechanical losses in a separate system with the tested motor driven by an additional motor and measuring the torque directly on the motor shaft.

The location of the measuring system's components is shown in Figures 8 and 9, whereas the set-up for the core loss measurements with a ring specimen is shown in Figure 10. Magnetizing winding was supplied from the APS-1102 GWINSTEC source (GWINSTEC, Taipei, Taiwan). This source ensured the keeping up the sinusoidal shape of the induction in the specimen core (in a wide range of induction). The waveforms of induced voltage and the magnetizing current were recorded, and then used by calculation algorithm to determine the core loss (thus omitted the problem of correctly determination of Joule loss in the magnetizing winding). Two types of ring cores were tested. The first one with relatively large diameters and small width, and the other one with relatively small diameters and large width. Ultimately, it was decided that the ring specimen with a larger 
diameter, being characterized by a more even induction distribution in the core, would be used during further research.

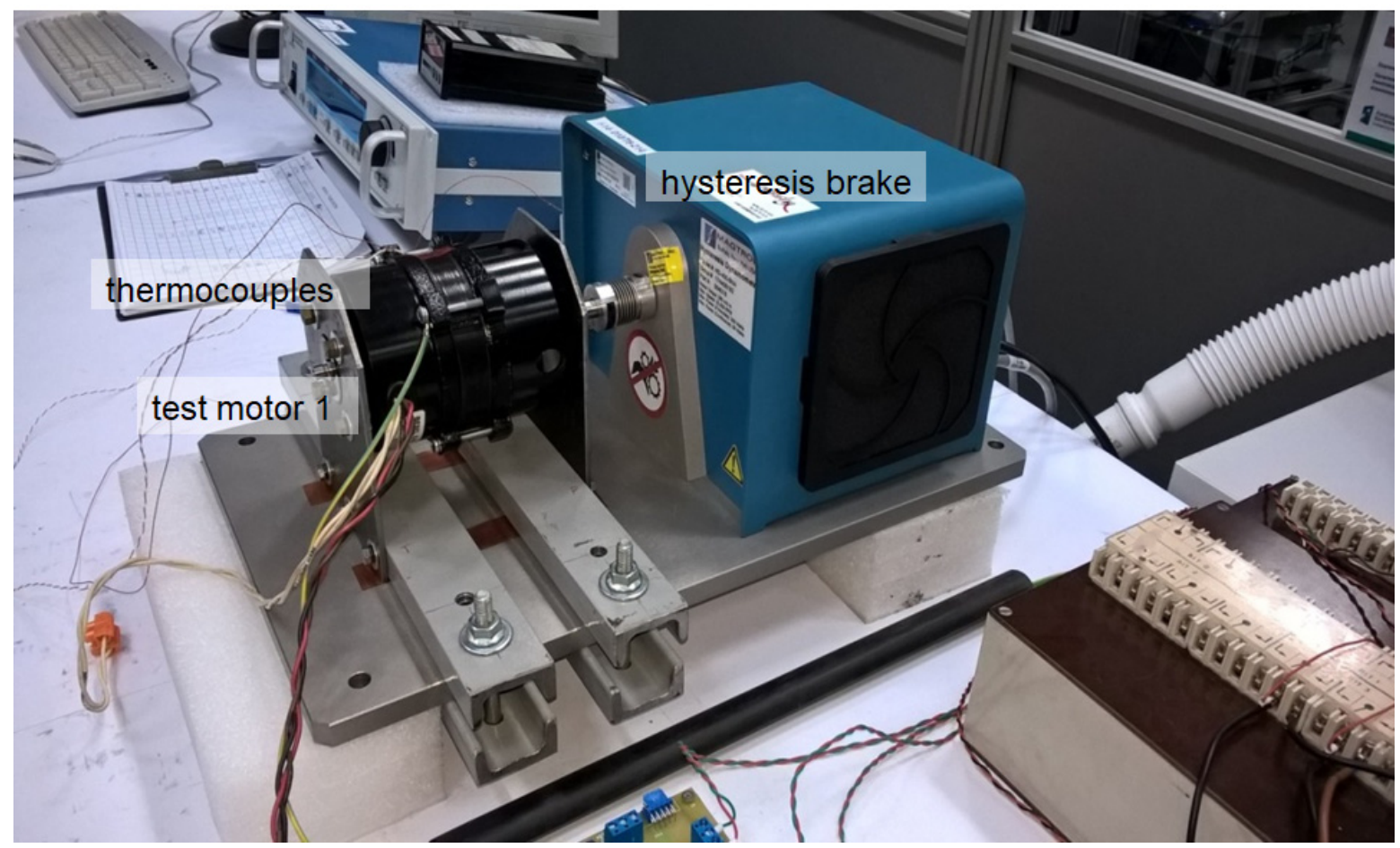

Figure 8. Experimental setup for measurements of core losses in investigated motors with test motor 1.

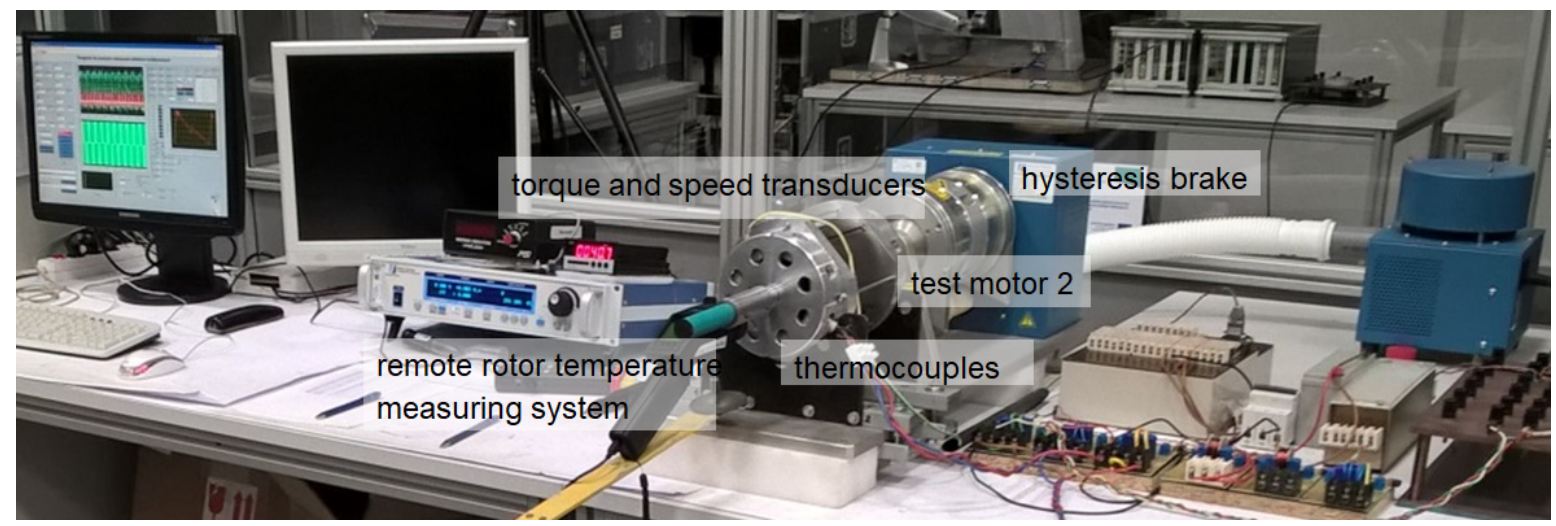

Figure 9. Experimental setup for measurements of core losses in investigated motors with test motor 2.

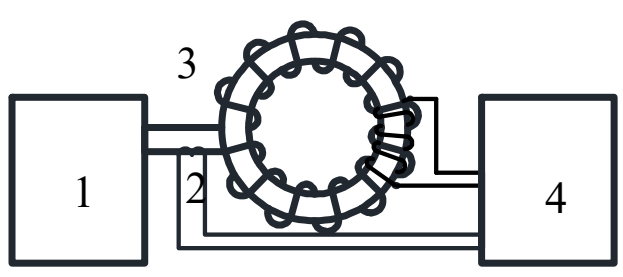

(a)

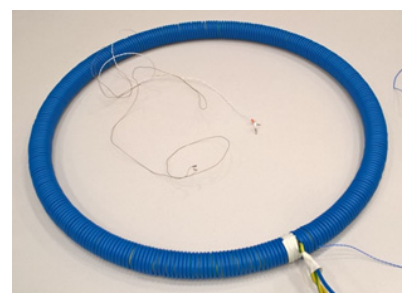

(b)

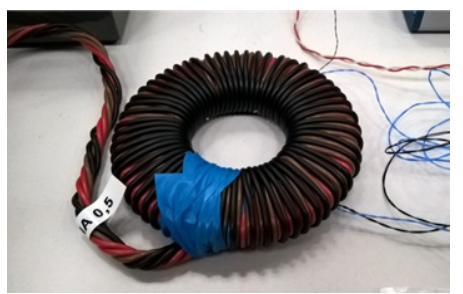

(c)

Figure 10. Experimental setup for the core loss measurements with a ring specimen (a): 1-power supply 100 VA frequency range: from $20 \mathrm{~Hz}$ to $20 \mathrm{kHz}, 2$ - current transducer, 3-sample wound with magnetizing and measuring windings, 4-data acquisition and processing unit; ring specimen width $10 \mathrm{~mm}$ (b); ring specimen width $30 \mathrm{~mm}$ (c). 


\section{Conclusions}

Scientific research carried out using the results of measurements carried out in various research systems (single strip tester, toroidal core, experimental setup containing the analyzed induction motors) allowed to formulate general conclusions, being in agreement with those available in literature (often referring to motors operating at $50 \mathrm{~Hz}$ frequency). It should be emphasized that the conducted studies concerned low power motors (having relatively small geometrical dimensions), operating at a frequency of 300 and $350 \mathrm{~Hz}$, for which the problem of correctly estimating additional iron loss in the stator and rotor core (pulsating losses, surface losses), is very important. In this context, the authors showed the results of laminations' specific iron loss estimation, for frequencies up to several $\mathrm{kHz}$, which is rarely discussed in the literature. In addition, as shown in the presented tables, it is important to use material characteristics dependent on the current width of the magnetic circuit element. Based on Figures 6 and 7 and Table 2, it can be concluded that the change in the magnetization characteristics caused by the core punching technology creates a very slight increase in the magnetizing current and, consequently, also in the current in the motor phase windings (for low power motors, magnetizing current reaches the level of $80-90 \%$ of the rated current). Taking into account the influence of the punching technology on the iron loss characteristics increases the basic iron losses in the core by $8 \%$ to $12 \%$, which results in an increase in total losses in the core from $5 \%$ to $7 \%$, and deterioration of efficiency by about $0.3 \%$ to $0.6 \%$, depending on the share of core losses in the total balance of motor losses.

The presented paper relates to the expansion and modernization of the induction motor analytical model, consisting in adjusting the algorithm to link the material characteristics of the magnetic circuit parts, taking into account the negative impact of the punching process, with their actual geometrical dimensions. It should be stated that the proposed analytical method enabling estimation of the damaged zone material characteristics and its width, is efficient and effective in cooperation with an modified induction motor model. Analyzing the obtained results, it should be stated that induction motor design process, relying on the results of measurements carried out on specimens having sizes other than geometrical dimensions of the motor parts (which means omission of the punching negative effects), leads to significant differences in operating parameters (e.g., motor efficiency), between the results of measurements and modeling-in the era of energy-saving motors such proceedings are inadmissible.

Author Contributions: Conceptualization, Z.G., M.D. and K.K.; methodology, Z.G., M.D. and K.K.; software, Z.G. and M.D.; validation, Z.G.; investigation, Z.G., M.D. and K.K.; resources, M.D.; writing-original draft preparation, Z.G., M.D. and K.K.; writing-review and editing, Z.G., M.D. and K.K.; supervision, Z.G., M.D. and K.K.; project administration, M.D.; funding acquisition, M.D. All authors have read and agreed to the published version of the manuscript.

Funding: This research was funded by National Science Centre (NCN) Poland as part of the "Opus - 18", grant number 2019/35/B/ST8/00764 "The manufacturing technology impact analysis of small-power high-speed electric motors to refine their analytical models."

Institutional Review Board Statement: Not applicable.

Informed Consent Statement: Not applicable.

Data Availability Statement: Data available on request due to research founder restrictions.

Acknowledgments: The authors would like to thank J. Szulakowski and W. Kubiak from the Technical University of Lodz for their work on measurements.

Conflicts of Interest: The authors declare no conflict of interest.

\section{Appendix A}

Determination of the iron loss in a conductive material leading time-varying magnetic flux, is possible by usage of Poyting's theorem, where the electromagnetic power $P$ flowing 
into a material, equals to the surface integral of normal component of the Poynting vector over the entire enclosed surface $A$ [19]:

$$
P=\oiiint_{A} S \cdot d A=\oiiint_{A} S_{n} d A
$$

where $\boldsymbol{S}=\boldsymbol{E} \times \boldsymbol{H}$ is the Poynting vector, $S_{n}$ is the normal component of the Poynting vector, $A$ is the entire enclosed surface.

By accepting a flat wave in consideration, we accept that is the simplest case of wave of alternating electromagnetic field. If the vectors $\boldsymbol{E}$ and $\boldsymbol{H}$ of electromagnetic wave are sinusoidal functions of time, then we can write the equation of envelopes of the wave amplitudes inside conductive material, as a $x$ distance function from the surface:

$$
H_{m x}=H_{m s} e^{-k x} e^{-j k x}
$$

where $H_{\mathrm{mx}}$ is the amplitude of magnetic field strength at $x$ distance from the surface (along $\mathrm{X}$ axis), $H_{\mathrm{ms}}$ is the amplitude of magnetic field strength at surface, $k=\sqrt{\pi f \mu \gamma}$ is the wave damping coefficient, $f$ is the frequency, $\mu$ is the material magnetic permeability, $\gamma$ is the material electrical conductivity, $x$ is the distance from the surface, to which the flat wave is falling, ), $j$ means the imaginary part of complex form.

The electric field intensity, can be determined by applying the first Maxwell's equation. Its $E_{\mathrm{my}}$ component is expressed as:

$$
E_{m y}=-\frac{(1+j) k}{\gamma} H_{m s} e^{-k x} e^{-j k x}=-\frac{\sqrt{2} k}{\gamma} H_{m s} e^{-k x} e^{-j\left(k x-\frac{\pi}{4}\right)}=-\sqrt{\frac{2 \pi f \mu}{\gamma}} H_{m s} e^{-k x} e^{-j\left(k x-\frac{\pi}{4}\right)}
$$

where $E_{\mathrm{my}}$ is the electric field intensity component (along $\mathrm{Y}$ axis).

By adopting the presence of single $\boldsymbol{H}$ and $\boldsymbol{E}$ vector components, we find the $P_{\mathrm{z}}$ active Poynting vector component, which is the iron loss in the conductive material, in the following form:

$$
P_{z}=\frac{1}{2} \sqrt{\frac{2 \pi f \mu}{\gamma}} H_{m s}^{2}
$$

\section{References}

1. Daem, A.; Sergeant, P.; Dupré, L.; Chaudhuri, S.; Bliznuk, V.; Kestens, L. Magnetic Properties of Silicon Steel after Plastic Deformation. Materials 2020, 13, 4361. [CrossRef] [PubMed]

2. Dems, M.; Komeza, K.; Kubiak, W.; Szulakowski, J. Impact of Core Sheet Cutting Method on Parameters of Induction Motors. Energies 2020, 13, 1960. [CrossRef]

3. Paltanea, G.; Manescu, V.; Stefanoiu, R.; Nemoianu, I.V.; Gavrila, H. Correlation between Magnetic Properties and Chemical Composition of Non-Oriented Electrical Steels Cut through Different Technologies. Materials 2020, 13, 1455. [CrossRef] [PubMed]

4. Strakowska, M.; Gmyrek, Z.; Wiecek, B. Application of IR thermography and thermal inverse modelling to evaluate power losses in ferromagnetic strips. Quant. Infrared Thermogr. J. 2018, 15, 54-67. [CrossRef]

5. Kouakeuo, S.H.; Deffo, Y.A.; Ducharne, B.; Morel, L.; Raulet, M.A.; Tsafack, P.; Garcia-Bravo, J.M.; Newell, B. Embedded printed magnetic needle probes sensor for the real-time control of the local induction state through a laminated magnetic core. J. Magn. Magn. Mater. 2020, 505, 166767. [CrossRef]

6. Nauwirth, T.; Backs, A.; Gustschin, A.; Vogth, S.; Pfeiffer, F.; Boni, P.; Schulz, M. A high visibility Talbot-Lau neutron grating interferometer to investigate stress-induced magnetic degradation in electrical steel. Sci. Rep. 2020, 10, 1764. [CrossRef] [PubMed]

7. Gmyrek, Z.; Cavagnino, A.; Ferraris, L. Estimation of the Magnetic Properties of the Damaged Area Resulting from the Punching Process: Experimental research and FEM Modeling. IEEE Trans. Ind. Appl. 2013, 49, 2069-2077. [CrossRef]

8. Leuning, N.; Steentjes, S.; Weiss, H.A.; Volk, W.; Hameyer, K. Magnetic Material Deterioration of Non-Oriented Electrical Steels as a Result of Plastic Deformation Considering Residual Stress Distribution. IEEE Trans. Magn. 2018, 54, 2001905. [CrossRef]

9. Boehm, A.; Hahn, I. Influence of geometric parameters and cutting edge deterioration on the differential inductances. In Proceedings of the 2014 IEEE 5th International Symposium on Sensorless Control for Electrical Drives, Hiroshima, Japan, 17-18 May 2014; pp. 1-6. [CrossRef]

10. Manescu, V.; Paltanea, G.; Ferrara, E.; Nemoianu, I.V.; Fiorillo, F.; Gavrile, H. Influence of mechanical and water-jet cutting on the dynamic magnetic properties of NO Fe-Si steels. J. Magn. Magn. Mater. 2020, 499, 166257. [CrossRef] 
11. Elfgen, S.; Steentjes, S.; Böhmer, S.; Franck, D.; Hameyer, K. Influences of Material Degradation Due to Laser Cutting on the Operating Behavior of PMSM Using a Continuous Local Material Model. IEEE Trans. Ind. Appl. 2017, 53, 1978-1984. [CrossRef]

12. Sundaria, R.; Lehikoinen, A.; Hannukainen, A.; Arkkio, A.; Belahcen, A. Mixed-order finite-element modeling of magnetic material degradation due to cutting. IEEE Trans. Magn. 2018, 54, 1-8. [CrossRef]

13. Jansson, E.; Thiringer, T.; Grunditz, E. Convergence of Core Losses in a Permanent Magnet Machine, as Function of Mesh Density Distribution, a Case-Study Using Finite-Element Analysis. IEEE Trans. Energy Convers. 2020, 35, 1667-1675. [CrossRef]

14. Bali, M.; de Gersem, H.; Muetze, A. Finite-Element Modeling of Magnetic Material Degradation Due to Punching. IEEE Trans. Magn. 2014, 50, 745-748. [CrossRef]

15. Elfegen, S.; Steentjes, S.; Bohmer, S.; Franck, D.; Hameyer, K. Continuous Local Material Model for Cut Edge Efects in Soft Magnetic Materials. IEEE Trans. Magn. 2016, 52, 1-4. [CrossRef]

16. Sundaria, R.; Lehikoinen, A.; Hannukainen, A.; Arkkio, A. Higher-order Finite Element Modeling of Material Degradation Due to Cutting. In Proceedings of the 2017 IEEE International Electric Machines and Drives Conference (IEMDC), Miami, FL, USA, 21-24 May 2017; pp. 1-6. [CrossRef]

17. Cossale, M.; Kitzberger, M.; Goldbeck, G.; Bramerdorfer, G.; Andessner, D.; Amrhein, W. Local Degradation in Soft Magnetic Materials: A Simplified Modeling Approach. IEEE Trans. Ind. Appl. 2019, 55, 5897-5905. [CrossRef]

18. Seo, U.-J.; Kim, D.-J.; Chun, Y.-D.; Han, P.-W. Mechanical Cutting Effect of Electrical Steel on the Performance of Induction Motors. Energies 2020, 13, 6314. [CrossRef]

19. Turowski, J.; Turowski, M. Engineering Electrodynamics. Electric Machines, Transformer and Power Equipment Design; CRC Press: Boca Raton, FL, USA, 2014; pp. 189-193.

20. Gmyrek, Z.; Cavagnino, A. Analytical Method for Determining the Damaged Area Width in Magnetic Materials Due to Punching Process. In Proceedings of the IECON 2011-37th Annual Conference of the IEEE Industrial Electronics Society, Melbourne, VIC, Australia, 7-10 November 2011; pp. 1764-1769. [CrossRef]

21. Dems, M.; Komeza, K. The Influence of Electrical Sheet on the Core Losses at No-Load and Full-Load of Small Power Induction Motors. IEEE Trans. Ind. Electron. 2017, 64, 2433-2442. [CrossRef] 